\title{
Properties of Anti-spalling Self-compacting Mortars - An Approach Towards Multifunctional Building Composite
}

\author{
Sher Baz Khan and Hamza Tahir
}

\begin{abstract}
This study investigates the micro structural studies of self-compacting mortars by the addition of PP, Nylon and Jute fibers and the amount of Gypsum formed. The amount of all fibers in the proposed mix was limited to $0.5 \%$ by weight of the mortar. Four types of mortars one of which was reference mortar and other three mortars contained PP, Nylon and Jute fibers of amount $0.5 \%$ by weight, respectively. The workability of the self-compacting mortars was monitored by Mini Slump Flow diameter test. From the results it was found that more compacted microstructure and less amount of Gypsum formation occurred for mortar samples containing PP fibers as compared to control mortar and mortar samples containing Nylon and Jute fibers respectively.
\end{abstract}

Index Terms - Gypsum, Microstructure, Mortar, Selfcompacting.

\section{INTRODUCTION}

Microstructure of construction material plays an important role in its durability. The performance of a construction material depends upon its microstructural characteristics. The property of any material to resist any deteriorating actions including abrasion and weathering actions is termed as the durability of that material [1]. Improvements in the microstructure of construction materials can possibly lead to the beneficial properties of the material.

In recent studies many approaches are adopted to improve the microstructure of mortars. Practice of hydrogen rich water is studied and found that more compacted and improved microstructure is observed by using hydrogen rich water in mortars [2]. The extent of cracks propagation and the cracks concentration was observed to be reduced by the addition of Polypropylene fibers combined with Metakaolin and Rice Husk Ash [3]. The effect of $\mathrm{pH}$ and the reaction of Fly ash particles in Geopolymer shown that the unreacted fly ash particles seen in the microstructure leaded to the poor mixing of geopolymer paste during preparation [4]. The Alkali Activated Fly ash based Geopolymer were studied and found that the microstructure contained unreacted FA particles and a sodium silicate gel formation that resulted to a loosely compacted microstructure [5]. Different fibers addition has been practiced in several

Submitted on February 2, 2021.

Published on February 12, 2021.

Sher Baz Khan, University of Engineering and Technology, Peshawar, Pakistan.

(e-mail: engrsherbaz ${ }^{\circledR}$ gmail.com)

Hamza Tahir, University of Engineering and Technology, Peshawar, Pakistan.

(e-mail: iamhamzatahir@gmail.com) researches to investigate their effect on mechanical properties like compressive strength and flexural strengths of a material. The effect of fibers addition on the microstructure of self-compacting mortars needs to be investigated and is not dealt in the recent researches.

In present work three types of fibers PP, Nylon and Jute fibers are added by the amounts of $0.5 \%$ by weight of selfcompacting mortars and then microstructure of resulting mortars is studied by using Scanning Electron Microscopy (SEM) analysis of mortars after 28 days of their hydration period. The amount of Gypsum formation and its deteriorating extent is also examined. The fibers are then compared on the basis of Gypsum formation and microstructure of the self-compacting mortars.

\section{EXPERIMENTAL}

\section{A. Materials}

Materials used for this study includes ordinary Portland cement that conforms ASTM C150 [6]. River sand that fulfills the requirements of ASTM C33 [7] is used as sand. for casting of specimens and their curing Portable water is used. Super Plasticizer used was Chemrite 303SP in accordance with ASTM C494 [8]. Class F Fly Ash was also used that conforms to ASTM C618 [9]. Three types of fibers PP, Nylon and Jute having lengths of $12 \mathrm{~mm}$ were used.

\section{B. Specimens Preparation}

For this study total of four self-compacting mortar mixes were prepared for which mix proportion adopted is shown in Table 1. Mortar cubes of sizes $50 \mathrm{~mm}$ were casted for each mortar mix. Mini slump flow diameter test was done to monitor the flow of self-compacting mortars. After casting the mortar cubes were cured for the period of 28 days. After curing all the cubes were oven dried at temperature of $105^{\circ} \mathrm{C}$. The microstructure of all the specimens was examined using SEM technique.

TABle 1: MiX Proportion of SElf COMPACTING Mortars (All Units

\begin{tabular}{|c|c|c|c|c|c|c|c|}
\hline Cement & $\begin{array}{l}\text { Fly } \\
\text { Ash }\end{array}$ & Water & $\begin{array}{l}\mathrm{W} / \mathrm{B} \\
\text { ratio }\end{array}$ & sand & $\begin{array}{c}\text { Super- } \\
\text { plasticizer }\end{array}$ & Fibers & Designation \\
\hline 630 & 70 & 250 & 0.35 & 1340 & 7 & 0 & $\begin{array}{l}\text { MRC (no } \\
\text { fiber) }\end{array}$ \\
\hline 630 & 70 & 250 & 0.35 & 1340 & 7 & 3.5 & $\begin{array}{c}\text { MRP }(0.5 \% \\
\text { PP fiber })\end{array}$ \\
\hline 630 & 70 & 250 & 0.35 & 1340 & 7 & 3.5 & $\begin{array}{l}\text { MRN } \\
(0.5 \% \\
\text { Nylon } \\
\text { fiber })\end{array}$ \\
\hline 630 & 70 & 250 & 0.35 & 1340 & 7 & 3.5 & $\begin{array}{c}\text { MRJ (0.5\% } \\
\text { Jute fiber) }\end{array}$ \\
\hline
\end{tabular}




\section{Testing Methods}

\section{1) Mini Slump Flow Diameter Test}

For examination of fresh property of self-compacting mortars mini slump flow diameter test was carried by following EFNERC criteria [10]. Mini slump cone was used for this purpose. The mini slump cone was filled and then was lifted slowly by allowing the self-compacting mortar flowing on the table. The perpendicular diameters for the flown mortar on table were recorded and the average of the two was taken as final flow for the mortars. Fig. 1 shows the measurement of Slump flow Diameter of the mortars.

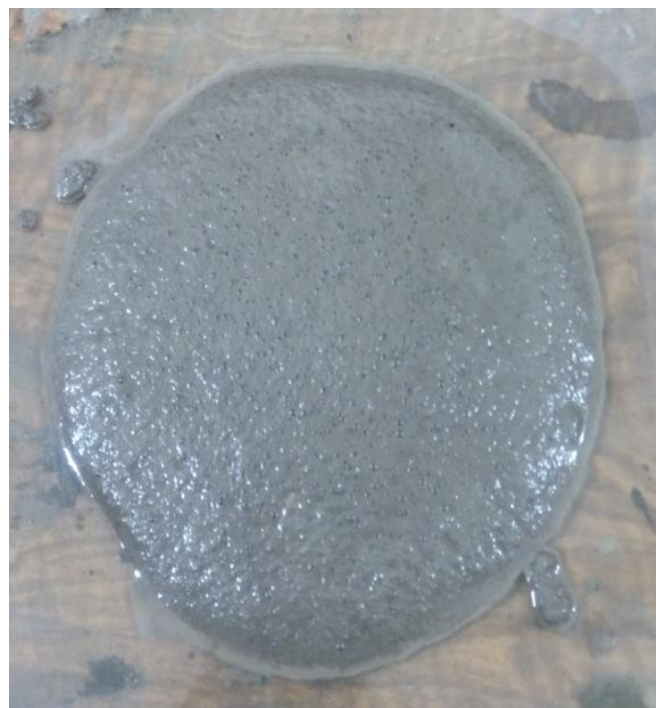

Fig. 1. Slump Flow Diameter measurement of mortars.

\section{2) SEM Analysis}

After 28 days of curing the mortar cubes were oven dried at $105{ }^{\circ} \mathrm{C}$ and then from each cube specific samples were prepared for SEM images. The SEM images were taken by using Scanning Electron Microscope. The samples prepared for SEM analysis and the Scanning Electron Microscope used are shown in Fig. 2 and Fig. 3, respectively.

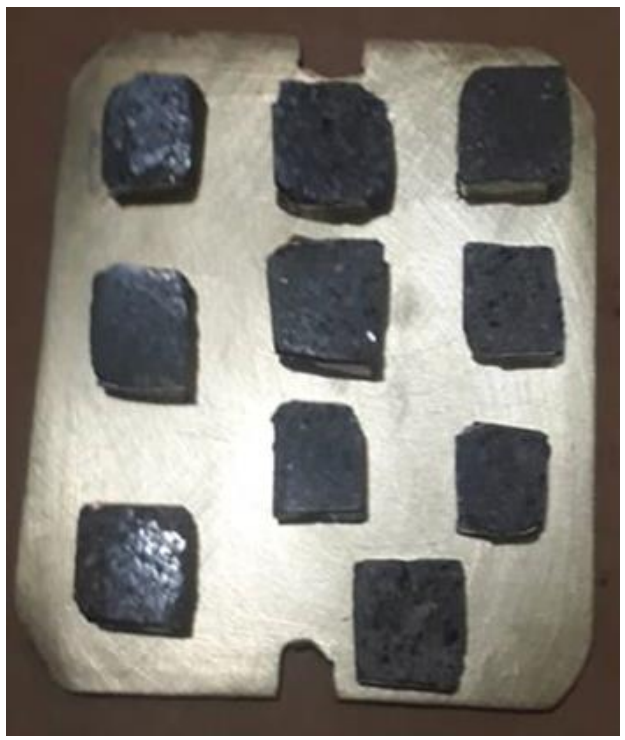

Fig. 2. Samples of SEM Analysis.

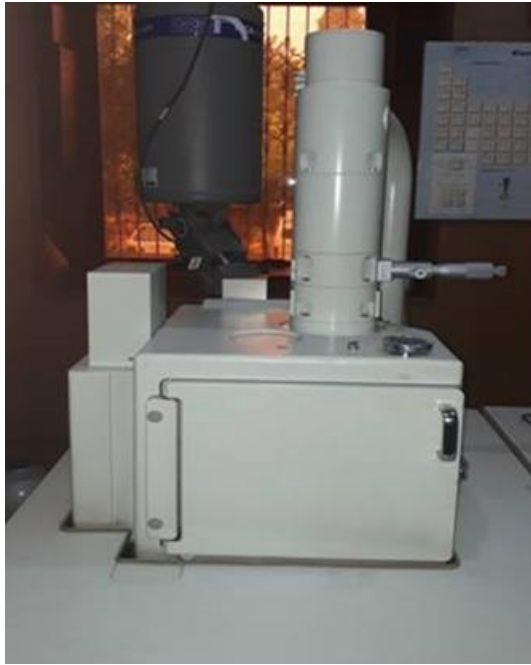

Fig. 3. Scanning electron microscope.

\section{RESULTS AND DISCUSSION}

\section{A. Slump Flow Diameter of Mortars}

For workability of self-compacting mortars Mini slump flow diameter test was conducted. Fig. 4 shows the final flow for all mortars i.e., Control mortar (MRC), mortar containing PP fibers (MRP), mortar containing Nylon fibers (MRN) and mortar containing Jute fibers (MRJ). From the results presented in Fig. 4, It is observed that the highest flow is observed for control mortar that is $241 \mathrm{~mm}$ and mortar mixes having PP, Nylon and Jute fibers undergo with slightly reduced flow characteristics i.e., $235 \mathrm{~mm}, 233 \mathrm{~mm}$ and $231 \mathrm{~mm}$ respectively. This reduction in the workability of mortars on addition of PP, Nylon and Jute fibers is due to the fact that the fibers make a network inside the mix and hence in this way viscosity of the mix is increased and flow is retarded [11]. Another reason for reduction in the workability by the addition of fibers may be due to the reason that the fibers having more surface area absorb the cement past hence increase the viscosity that results in reduced flow of mortar mixes having fibers as constitutes [12]. It could also be seen from the results that the mortar mix containing PP fibers has better workability as compared to mortars containing Nylon and Jute fibers. This shows that PP fibers provide good flow property to the mortars as compared to Nylon and Jute. The results also show that the lowest value of slump flow is that for mortar mix having Jute fibers.

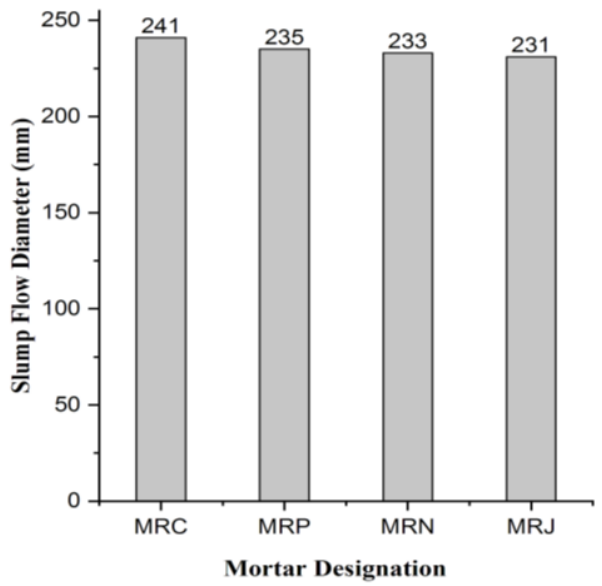

Fig. 4. Slump flow diameter of self-compacting mortars. 


\section{B. Microstructure of Specimens}

SEM images of all mortar specimens are shown in Fig. 5. Fig. 5 (a) shows the SEM image of reference or control mortar sample. Fig. 5 (b) shows the SEM image for mortar sample containing PP fibers. Fig. 5 (c) shows SEM image of mortar sample containing Nylon fibers while Fig. 5 (d) shows SEM image of mortar sample having Jute fibers. From SEM images shown in Fig. 5, it can be observed clearly that more improved and denser microstructure is seen for mortar samples containing PP, Nylon and Jute fibers as compared to the mortar sample having no fibers. In control mortar sample the pores are clearly visible that may result to a poorly compacted microstructure. More extent of formation of Gypsum is observed in control mortar sample as compared to other mortar samples containing PP, Nylon and Jute fibers. This shows that more deterioration on control sample might occur due to more amount of formation of Gypsum in it. Moreover, on comparison of SEM images it could be seen that relatively more compacted and improved microstructure can be seen for mortar sample containing PP fibers as compared to mortar samples containing Nylon and Jute fibers. This shows best performance of PP fibers in microstructure improvement as compared to Nylon and Jute fibers. The fibers used retard the propagation of cracks and their widening inside the mortars that may lead to improved durability property of mortars.
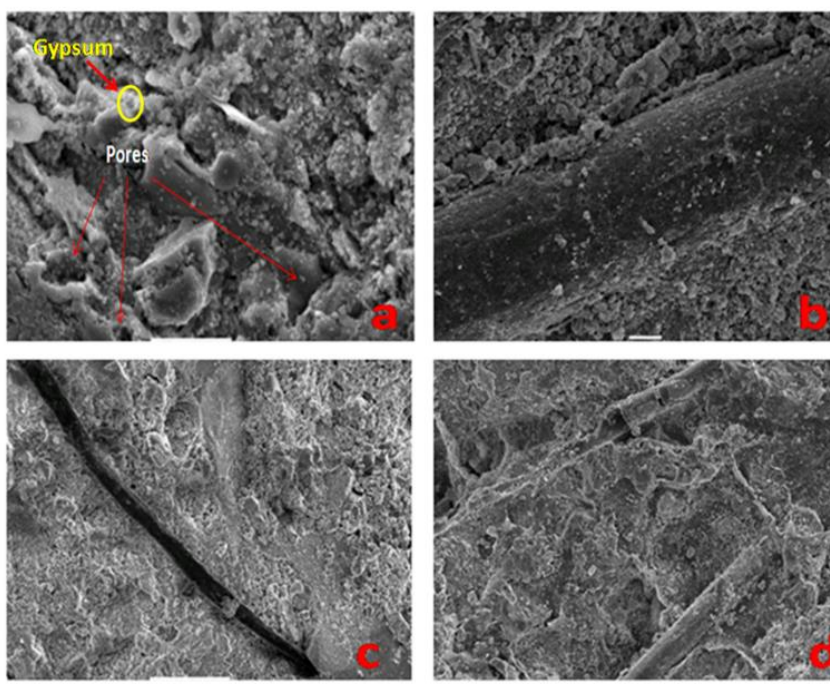

Fig. 5. (a) SEM image of control mortar sample (MRC), (b). SEM image of mortar sample containing PP fibers (MRP), (c)SEM image of mortar sample containing Nylon fibers (MRN), (d) SEM image of mortar sample containing Jute fibers (MRJ).

\section{CONCLUSIONS}

From the results it is concluded that, the workability of self-compacting mortars is reduced by the addition of PP, Nylon and Jute fibers. By addition of fibers the fibers are seen interlocking the cracks in the microstructure. On comparison it is concluded that more improved microstructure is seen for mortar containing PP fibers as compared to the mortars containing Nylon and Jute fibers. More extent of Gypsum formation is observed for control sample while for mortars containing fibers have less amount of Gypsum formation. Control mortar is more prone to deterioration as compared to mortar samples containing fibers due to more extent of Gypsum formation as seen in SEM images.

\section{ACKNOWLEDGMENT}

We would like to thank Dr. Yasir Irfan Badrashi, Assistant Professor at Civil Engineering Department UET Peshawar Bannu Campus, for his throughout help during the research work and in drafting this paper.

\section{REFERENCES}

[1] P. K. M. a. P. J. M. Monteiro, CONCRETE: Microstructure, Properties and Materials, 2001.

[2] B. W. Jo, M. A. Sikandar, S. Chakraborty, and Z. Baloch, S Chakraborty and Z. Baloch, "Investigation of the acid and sulfate resistance performances of hydrogen-rich water-based mortars," Construction and Building Materials, vol. 137, pp. 1-11, 2017.

[3] E. Mohseni, M. A. Yazdi, B. M. Miyandehi, M. Zadshir and M. M. Ranjbar, "Combined Effects of Metakaolin, Rice Husk Ash, and Polypropylene Fiber on the Engineering Properties and Microstructure of Mortar," Journal of Materials in Civil Engineering, vol. 29 , no. 7, 2017.

[4] E. Arioz, O. Arioz and M. O. Kockar, "An Experimental Study on the Mechanical and Microstructural Properties of Geopolymers, Procedia Engineering, vol. 42, pp. 100-105, 2012.

[5] M. N. Mužek, D. Jozić and J. Zelic, "Microstructural Characteristics of Geopolymers Based on Alkali-Activated Fly Ash," Chemical and Biochemical Engineering Quarterly, vol. 26, no. 2, pp. 89-95, 2012.

[6] ASTM, ASTM-C150/C150M-16: Standard specifications for portland cements.

[7] ASTM, STM C33 / C33M - 18: Standard Specification for Concrete Aggregates.

[8] ASTM, ASTM C494 / C494M - 19: Standard Specification for Chemical Admixtures for Concrete.

[9] W. B. Butler, A Critical Look at ASTM C 618 and C 311, 1982.

[10] S. U. Association House, Specification and Guidelines for SelfCompacting. Concrete, 2002.

[11] C. Jiang, S. Huang, Y. Zhu, Y. Lin and D. Chen, "Effect of Polypropylene and Basalt Fiber on the Behavior of Mortars for Repair Applications," Advances in Materials Science and Engineering, 2016.

[12] B. Chen and J. Liu, "Contribution of hybrid fibers on the properties of the high-strength lightweight concrete having good workability," Cement and Concrete Research, vol. 35, no. 5, pp. 913-917, 2005.

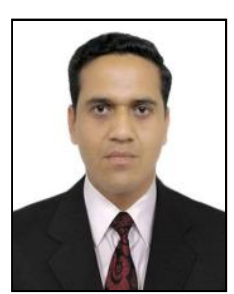

\section{Sher Baz Khan}

Graduated in Civil Engineeing (2016) and enrolled in Master in Civil Engineering, both by the University of Engineering and Technology, Peshawar.

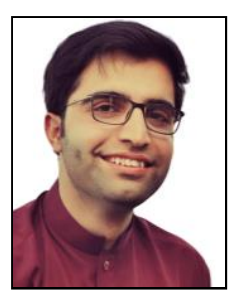

\section{Hamza Tahir}

Graduated in Civil Engineeing (2020) by the University of Engineering and Technology, Peshawar. 